\title{
Non-linear mechanical behavior of a sintered material for braking application using digital image correlation
}

\author{
Ruddy Mann ${ }^{1, *}$, Vincent Magnier ${ }^{1}$, Itziar Serrano-Munoz ${ }^{1}$, Jean-Francois Brunel ${ }^{1}$, Florent Brunel ${ }^{1}$, \\ Philippe Dufrenoy ${ }^{1}$, and Michele Henrion ${ }^{2}$ \\ ${ }^{1}$ Université Lille, CNRS, Arts et Métiers Paris Tech, Centrale Lille, FRE 3723 - LML, Lille, France \\ ${ }^{2}$ Faiveley Transport Gennevilliers, 92230 Gennevilliers, France
}

Received: 21 September 2016 / Accepted: 27 September 2017

\begin{abstract}
Friction materials for braking applications are complex composites made of many components to ensure the various performances required (friction coefficient level, low wear, mechanical strength, thermal resistance, etc.). The material is developed empirically by a trial and error approach. With the solicitation, the material evolves and probably also its properties. In the literature, the mechanical behavior of such materials is generally considered as linear elastic and independent of the loading history. This paper describes a methodology to characterize the mechanical behavior of such a heterogeneous material in order to investigate its non-linear mechanical behavior. Results from mechanical tests are implemented into material laws for numerical simulations. Thanks to the instrumentation, some links with the microstructure can also be proposed. The material is made of a metallic matrix embedding graphite and ceramic particles and is manufactured by sintering. It is used for dry friction applications such as high-energy brake for trains, cars and motorcycles. Compression tests are done with digital image correlation to measure full-filled displacement. It allows to calculate strain fields with enough resolution to identify the material heterogeneity and the role of some of the components of the formulation. A behavior model of the material with plasticity and damage is proposed to simulate the non-linear mechanical behavior and is implemented in an FEM code. Results of mechanical test simulations are compared with two types of experiments showing good agreement. This method thus makes it possible to determine mechanical properties at a virgin state but is extensible for characterizing a material having been submitted to braking solicitations.
\end{abstract}

Keywords: Sintered material / DIC / loading history effect / constitutive law

\section{Introduction}

The tendency of reducing the number of components and expanding vehicle performances leads to an increase of the energy dissipation of dry friction brakes. In the railway sector, the temperatures reached by the friction pair, disc and pad, could be very high, i.e. up to $1000^{\circ} \mathrm{C}$ locally at the friction surface. Pad friction materials are complex due, on the one hand to these high temperatures, and on the other hand to the various key performance parameters that have to be achieved: high and constant tribological performances whatever the conditions; good wear resistance; high mechanical strength; low propensity to acoustic emissions; etc. These multiple requirements lead to composite materials including a large number of components (generally more than 10) with a metallic matrix to withstand very high temperatures.

\footnotetext{
* e-mail: ruddy.mann@gmail.com
}

The mechanical behavior of the friction material is important regarding its influence on the contact distribution, the tribological performances, the thermomechanical behavior, the dynamical behavior and consequently the squeal propensity, etc.

The mechanical properties of a material are usually determined by static compressive or dynamic tests, with samples machined in the pads [1]. The mechanical behavior is considered as either elastic, linear or nonlinear according to its formulation. Sintered friction materials are generally deemed to be as linear elastic that is not necessarily verified [2]. A significant drawback is that these characterizations are done in a virgin state [36]. However, loading levels are very high and necessarily lead to material modification and the evolution of properties. There is thus a need to develop a general method allowing characterization of mechanical properties with non-linear behavior and for a variety of material states. This is the first motivation of this work. 
The development of friction material for brakes is based on a trial-and-error methodology for the definition of material formulations by dyno tests due to the misunderstanding of the relationship between formulation and properties. But in recent contexts, this way to proceed is long and expensive and becomes less and less acceptable especially with the environmental and safety norms becoming increasingly restrictive. Efforts must be made to understand the link between the development and performances of the friction materials. It is therefore important to be able to link formulation and properties, that is the second motivation of this work.

From these considerations, it is necessary to develop new strategies of material properties characterization to identify non-linear behavior that could be used in braking simulations and to get relationships with the microstructure. This is the aim of the present paper.

In the literature, numerous studies on pad design highlight the important role of mechanical properties. Minimal models or models based on the real geometry using the finite element method have been developed to study the macroscopic parameters of the material, like the coefficient of friction, as well as mechanical and thermal properties [710]. It is clear that mechanical properties have an important role on contact pressure uniformity and consequently on the thermal distribution and tribological performances, on the stiffness of components and consequently on the dynamic behavior, etc.

Various techniques are used to characterize the material mechanical properties:

- compressive tests, generally performed on cubic, rectangular or cylindrical samples extracted from pads;

- dynamic characterization also often carried out by compression;

- ultrasonic measurements based on the relationship between the elastic modulus and acoustic wave propagation.

Using these techniques, a global value of the elastic modulus or in the best case, a bulk non-linear behavior, is obtained. It might be a strong assumption to take into account a bulk elastic modulus considering that the behavior could be non-linear.

But above all, the material is modified with the thermal-mechanical loading and consequently also its properties, and that is rarely considered in the literature. Finally, these characterizations give modulus values at the macroscale without any explanations of these results from the microstructure or components behavior observed during the tests. Note that one difficulty is the necessity to extract specimens from the pad, as the manufacturing process is very difficult to reproduce on small samples.

Recently, studies have been performed involving the introduction of heterogeneities in friction material by using a homogenization technique $[11,12]$. These first attempts are very promising but require experimental data of the geometry and properties of the component material that are difficult to obtain.

The non-linear and loading dependent behavior of friction materials is one of the main drawbacks in current simulations on braking issues. In this work we propose a methodology to characterize these complex materials in terms of non-linear behavior and to identify links with the microstructure. This methodology is adapted to constraints of sample machining from pads and can be applied to the material before and after testing to investigate the behavior evolution. The proposed methodology involves incorporating digital image correlation (DIC) techniques during a specific compressive test. This technique gives information of displacement and strain fields at the microscale allowing connections between the global mechanical behavior and the corresponding mechanisms of heterogeneous materials [13-19]. From the DIC results, a mechanical behavior model is established and implemented into material laws for numerical simulations.

The paper is divided into three parts. First, the material and the test protocol are described, with specific details for the DIC sample preparation. A first test was performed to validate the technique by comparison with strain gauges measurements. Tests with increasing loads were then performed to identify the non-linear material behavior and the relationship with micro-scale mechanisms thanks to DIC. In the last part, a non-linear material behavior model identification approach is proposed. It was implemented in a FEM code and validated to be implemented in braking simulations.

\section{Description of the material and the experimental methods}

\subsection{Presentation of the sintered material}

The material studied in this paper is an industrial formulation of a sintered material for railway applications and its global composition is given in Table 1.

This material is obtained by compacting powders of components, before being sintered at high temperature (below the melting temperature of the constituents). It is clear that it has a very complex microstructure as shown in Figure 1, with components of different types and sizes. Moreover, according to Figure 1, the presence of porosities was confirmed, localized mainly within the graphite particles that are porous materials.

\subsection{Specific compressive tests for mechanical behavior}

Due to its microstructure, the sintered material has a nonsymmetric behavior in traction-compression. Furthermore, during braking, the sintered material of the pads is submitted to compressive loading onto the disc. The usual technique to characterize its behavior is through compressive tests.

Conventional compressive tests are carried out with cylindrical samples having standardized dimensions. Since a flat sample surface is required when using the DIC, and the samples are directly extracted from braking pads that have a reduced thickness, it has been necessary to develop a specific test involving compression on cubic sample to characterize the behavior of the sintered material. 
Table 1. Composition of a metallic matrix sintered material.

\begin{tabular}{lll}
\hline Components & Size of particles & Ratio in mass $(\%)$ \\
\hline Fe-Cu matrix & $100-600 \mu \mathrm{m}$ & 70 \\
& $100-200 \mu \mathrm{m}$ & \\
Ceramics & $100-250 \mu \mathrm{m}$ & 10 \\
& $100-600 \mu \mathrm{m}$ & \\
Graphites & $400-1100 \mu \mathrm{m}$ & 20 \\
\hline
\end{tabular}

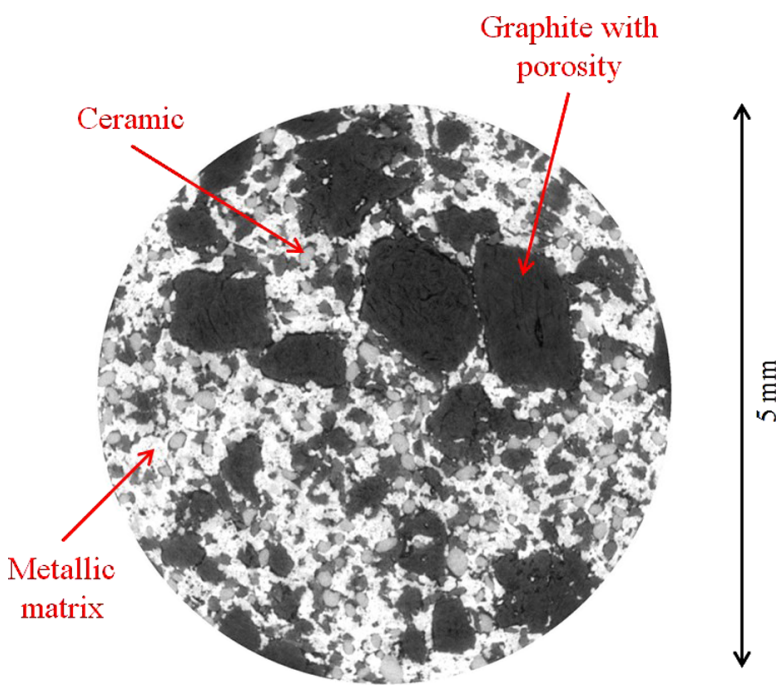

Fig. 1. SEM micrograph of the sintered material.

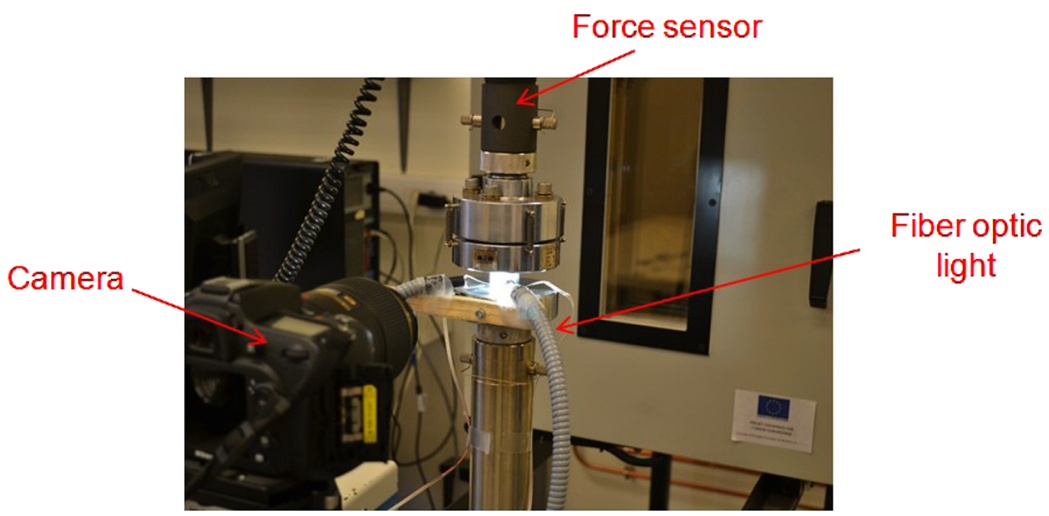

Fig. 2. Illustration of the compressive test and instrumentation.

\subsubsection{Compressive test and instrumentation}

During the compressive test, the sample is placed between two rigid plates and submitted to a compressive load at a slow strain rate $(0.01 \mathrm{~mm} / \mathrm{s})$.

To control the parallelism of the two plates used with this test, a compressive test without sample is made at $10 \mathrm{kN}$ plate against plate with a free ball joint at the upper plate. The ball joint is tightened when the maximum load is applied to reduce the parallelism default. An illustration of the test is presented in Figure 2.

The instrumentation includes a force sensor, a fiber optic light, and a Ximea camera (4 million pixels) to acquire data during the test necessary to the DIC.

Pictures taken with the camera during the test enable the identification of displacement fields which make it possible to determine the evolution of mechanical properties by DIC. The DIC consists to find the transformation between a reference picture and a distorted one by analyzing the pixel displacement of an applied surface speckle pattern observed by the camera during loading [20]. For the DIC-analysis presented in this paper, the software YADICS [21] has been used.
To obtain DIC results independent of microstructure, an artificial texture is created with black paint in the background on which a surface speckle pattern was applied with an airbrush on the surface observed by the camera. The painted spot size was approximatively $20-30 \mu \mathrm{m}$. The dimensions of the sample and camera lens gave the relation: 1 pixel $=5 \mu \mathrm{m}$.

\subsubsection{Tested samples}

The samples tested in this paper were directly machined from the pad with a diamond wire. Due to the limited pad thickness in the normal direction and the necessity of a flat surface for the DIC, cubic specimens of $20 \mathrm{~mm}$ were extracted. Compared to the brake pad component sizes, the dimensions of the samples were chosen to establish a representative macroscopic behavior model of the sintered material.

To ensure the quality of the results, the preparation of the sample was controlled by reducing the parallelism error between the upper and lower surfaces. It was obtained after the sample extractions by iterative phases of cubic surface grinding and metrology control until an acceptable default is obtained $(<20 \mu \mathrm{m})$. 
Table 2. Test sequence.

\begin{tabular}{lllrrr}
\hline Level number & 1 & 2 & 3 & 4 & 5 \\
Compressive load level (MPa) & 3 & 5 & 10 & 15 & 20 \\
Number of cycles & 4 & 4 & 10 & 10 & 10 \\
\hline
\end{tabular}
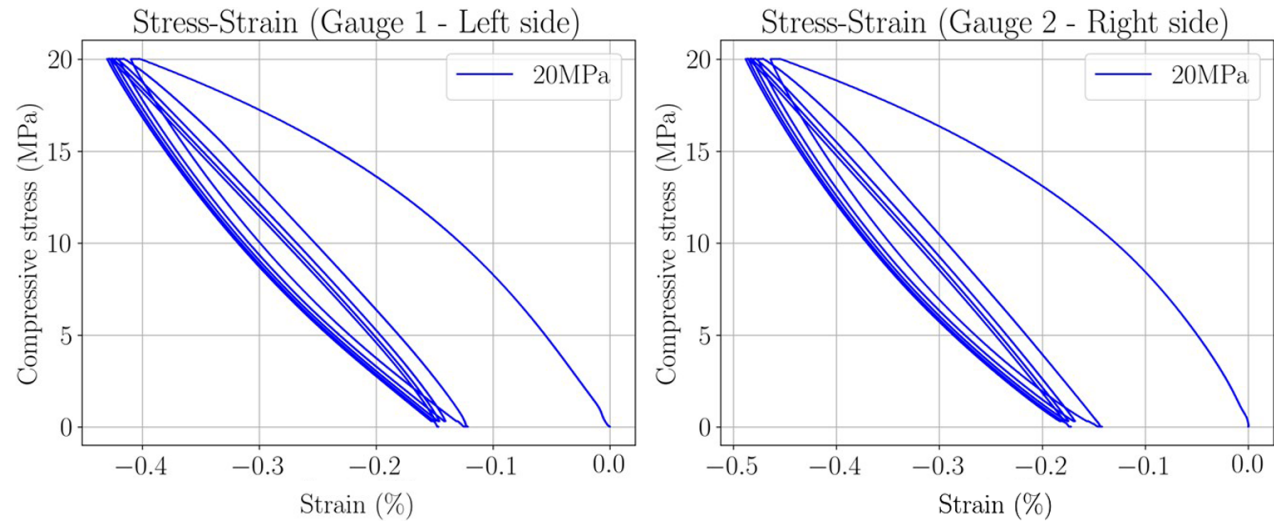

Fig. 3. Stress-strain curves from the gauges for the compressive preliminary test at $20 \mathrm{MPa}$.

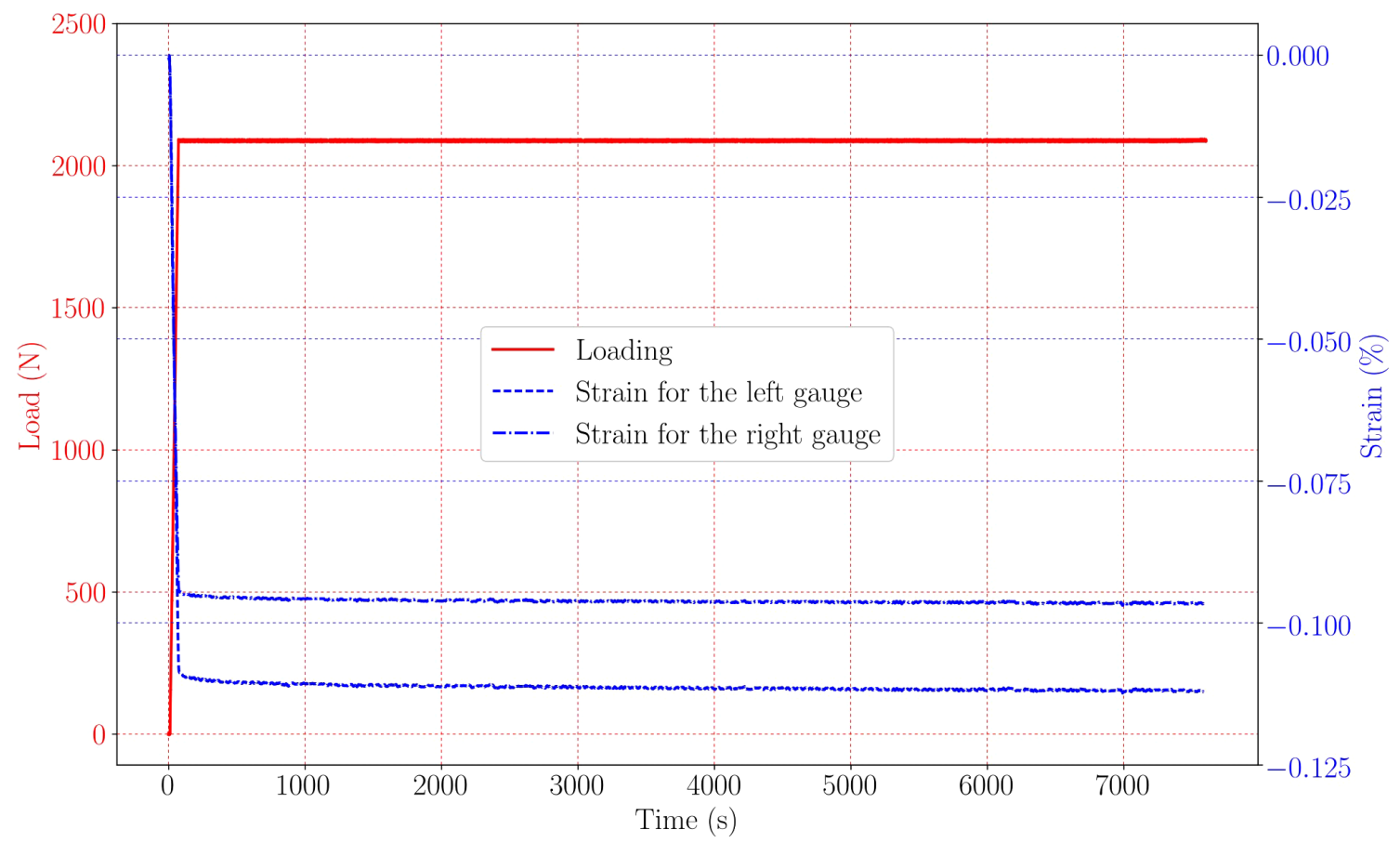

Fig. 4. Creep results in strain-time curves at $5 \mathrm{MPa}$.

Note that the full-filed measurement given by DIC also makes it possible to analyze the uniformity of the compressive loading on the surface. Two strain measurement techniques are used during the test:

- two strain gauges were glued on the lateral sides on the sample in the compressive direction (grid size of $5 \mathrm{~mm}$ ); - the DIC technique with a speckle pattern applied on the front face of the 175 samples observed by the camera during the test.

These two ways of strain measurement are used with the first idea to compare the values of the two strain gauges to control the default parallelism, and secondly to compare gauges results with the DIC mean strain value to validate the volume-related representativeness of the observed surface.

\subsubsection{Test procedure}

In order to evaluate the loading history effect in a sintered material sample extracted after manufacturing, a test procedure was made with different load levels applied to the same sample. The compressive load levels were directly extracted from the railway braking application. The test sequence is given in Table 2 . 


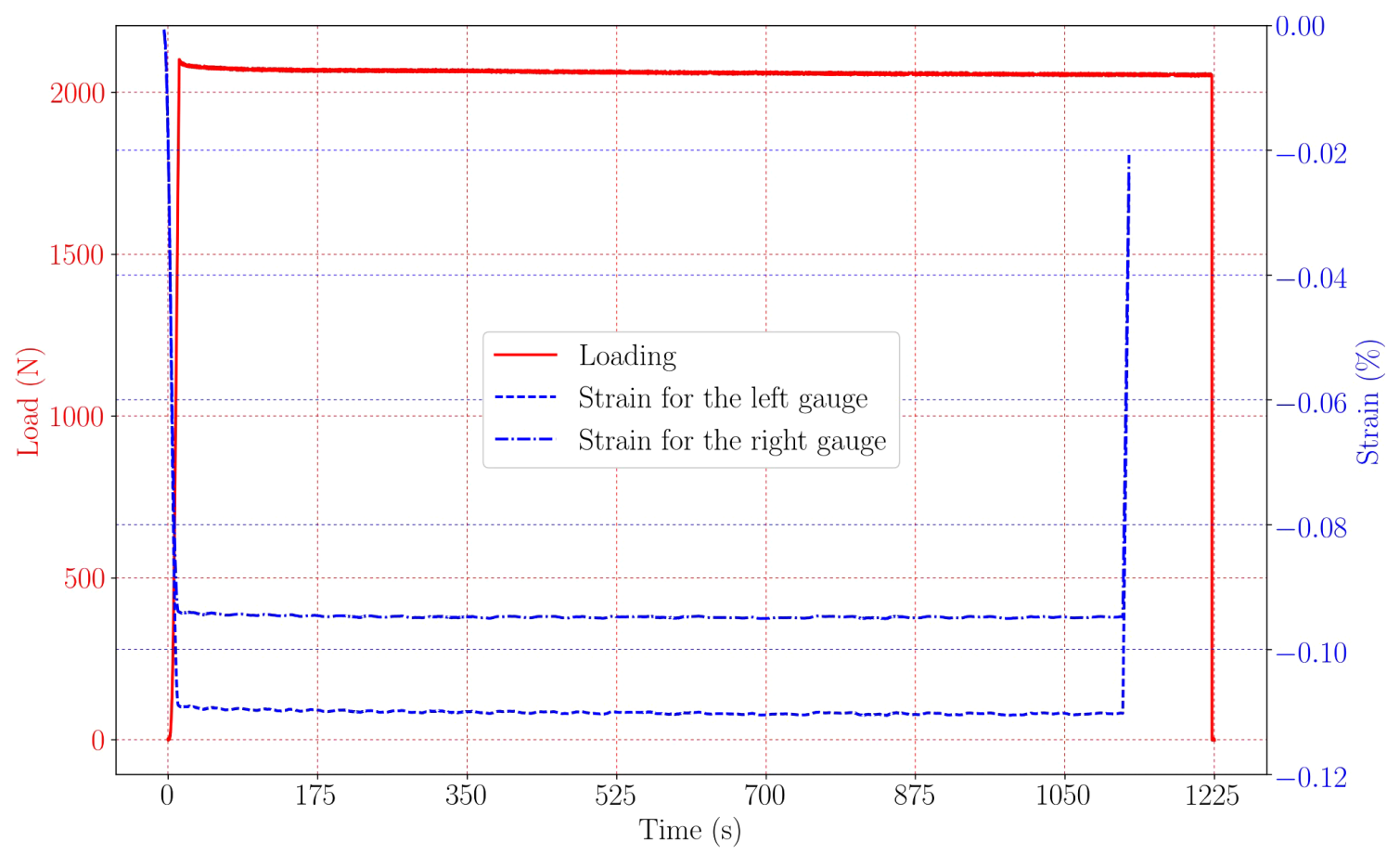

Fig. 5. Relaxation results in strain-time curves with an initial load of $5 \mathrm{MPa}$.

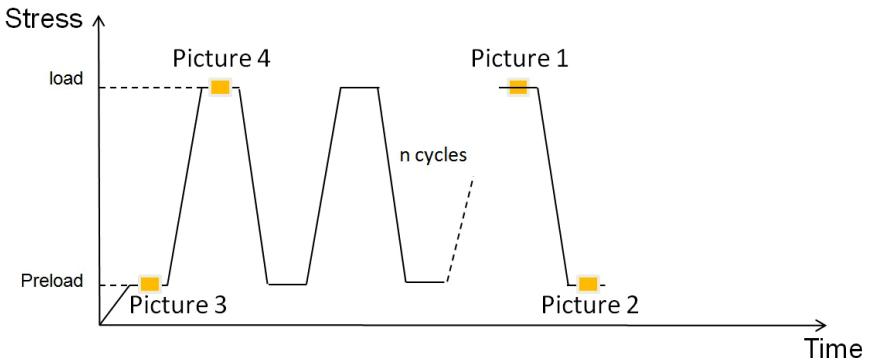

Fig. 6. Explanation of the pictures used in DIC to extract the results.

Several cycles were applied at each load level, and a preload was applied before each load level to avoid rotation of the sample at low load levels $(0.3 \mathrm{MPa})$.

The results section has been divided into two parts. Firstly, the different ways of strain evaluation were compared during a pre-test at a load level of $20 \mathrm{MPa}$ applied on a separate sample. This part allowed an understanding of the stages in DIC to obtain the strain field and the validation of DIC results by comparison with the gauges. Secondly, results of the test sequence of Table 2 are presented, illustrating the loading history of the sintered material.

\section{Compression tests}

\subsection{Preliminary test: compressive test at $20 \mathrm{MPa}$}

In order to explain the different steps from the experimental test to the DIC results, a preliminary test in compression was done on a cubic sample at a single load level of $20 \mathrm{MPa}$. This pre-test was used to validate the DIC results in order to identify the mechanical behavior of the sintered material.

\subsubsection{Strain gauge results}

Figure 3 shows the evolution of the two gauges. For the first loading cycle, the two gauges do not have the same magnitude probably due to the impact of the parallelism defect although it is less than $20 \mu \mathrm{m}$. However for the following loading cycles, strain amplitudes on the lateral sample surfaces had close magnitudes, corresponding to a global uniform compression of the sample. The cycles were linear under compression and non-linear during unloading. Such a hysteresis could be due to the viscoelasticity, or to a dissipative effect, or again to friction in the contact with the plates. Successive cycles exhibited an increase of residual strain that could be due to damage or creep effects. This will be discussed in the following.

The gauges gave a mean strain value near $0.35 \%$ at $20 \mathrm{MPa}$ that will be compared with the results of the DIC measurements in the following.

\subsubsection{Creep and relaxation}

Creep and relaxation tests have been performed and the results are illustrated in Figures 4 and 5.

For the creep experiments, a compressive test at constant load on a cubic sample of $20 \mathrm{~mm}$ was performed during $2 \mathrm{~h}$ at $5 \mathrm{MPa}$ with a $2000 \mathrm{~N} / \mathrm{min}$ load speed at ambient temperature. Two strain gauges were glued to the lateral sides of the sample as previously explained.

During this test, any strain evolution appeared after $2 \mathrm{~h}$, indicating that there was almost no creep in the material at ambient temperature. 


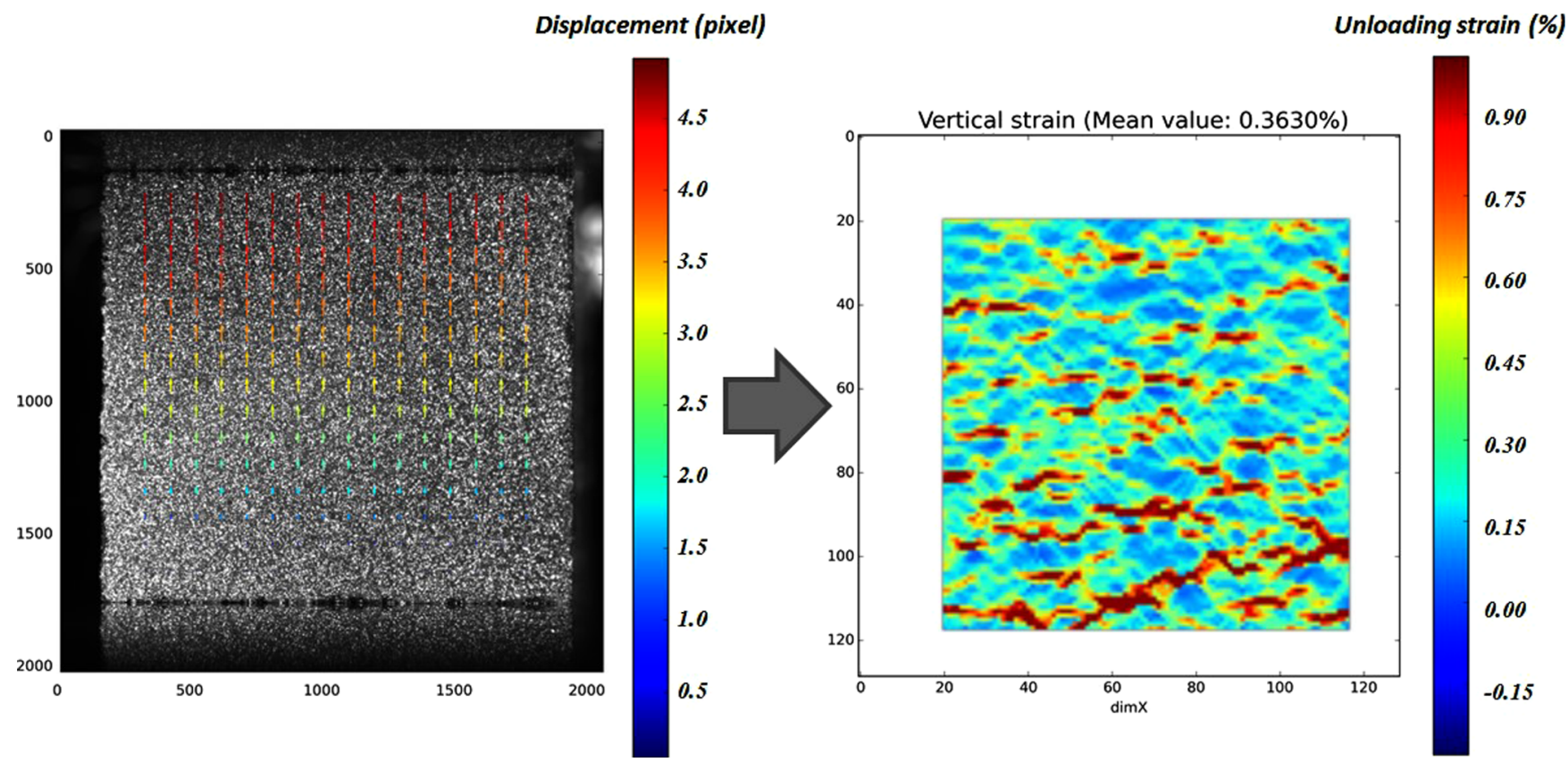

Fig. 7. Displacement and strain field obtained by derivation during unloading at $20 \mathrm{MPa}$.

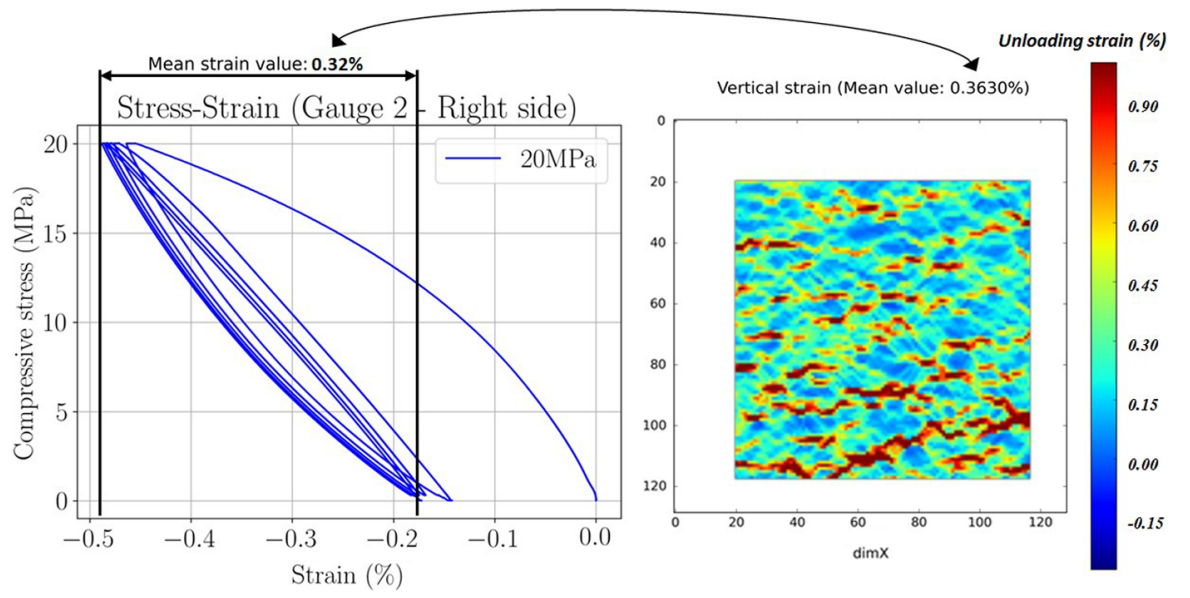

Fig. 8. Comparison between DIC and gauges for the last cycle.

For the relaxation experiment, a compressive test at constant strain on a cubic sample of $20 \mathrm{~mm}$ was performed for $20 \mathrm{~min}$ with an initial pressure of $5 \mathrm{MPa}$, a load speed of $2000 \mathrm{~N} / \mathrm{min}$, and at ambient temperature. Two strain gauges were glued onto the lateral sides of the sample.

During this test, $30 \mathrm{~N}$ of the $2083 \mathrm{~N}$ initially applied on the sample were lost in $20 \mathrm{~min}(1.44 \%)$. There was almost no relaxation for this material at ambient temperature.

\subsubsection{Exploitation of DIC results}

According to previous tests that have demonstrated the absence of creep and relaxation with this material at ambient temperature, pictures have to be chosen at specific times to obtain elastic and residual strain fields to determine the mechanical behavior of the material.
The elastic strain can be extracted during the unloading by a correlation between images 1 and 2 (2-1), as illustrated in Figure 6, in order to determine the elastic modulus. These pictures correspond to the last cycle of a load level.

The DIC results are presented in Figure 7. On the lefthand side, the displacement field during the unloading of the last cycle at $20 \mathrm{MPa}(2-1)$ is illustrated. By derivation of the displacement field, vertical, horizontal and local shear local strain could be determined. To the right, the corresponding vertical strain field during unloading is presented. Because the results were given for the unloading of the compressive test (2-1), the displacement and vertical strain fields had positive values.

To validate the volume-related representativeness of the surface observed with DIC in terms of mechanical behavior, a comparison between the vertical strain value extracted from the strain gauges on the lateral sides and the 

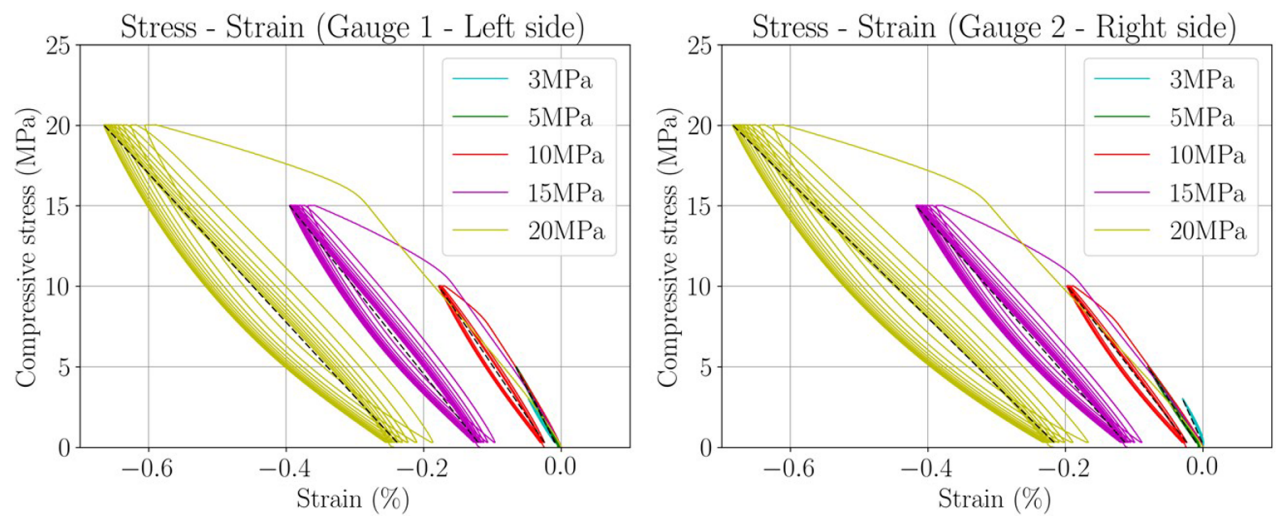

Fig. 9. Gauge results as stress-strain curves for each load level.

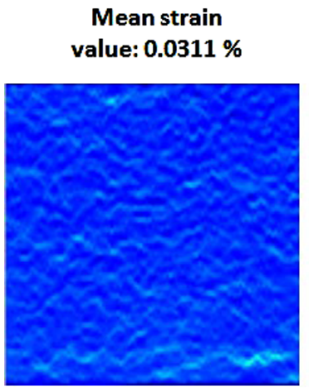

उMPa

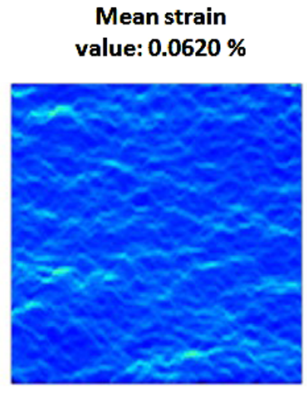

$5 \mathrm{MPa}$

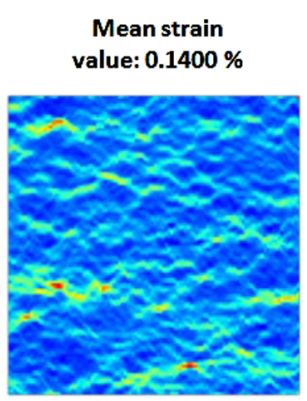

$10 \mathrm{MPa}$

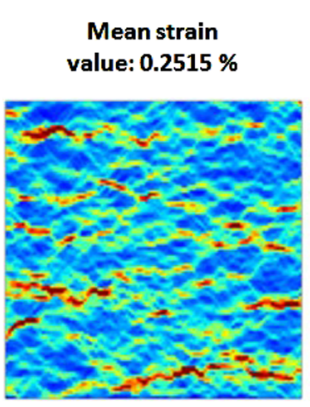

$15 \mathrm{MPa}$

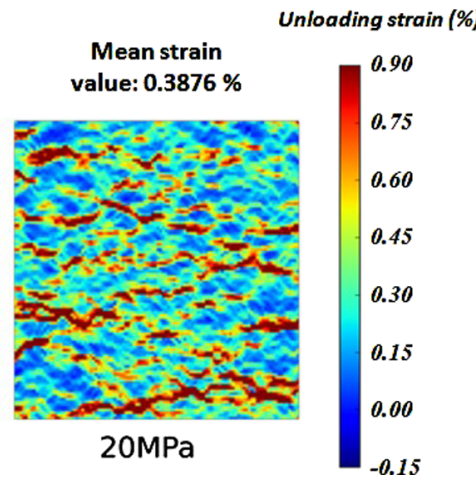

Fig. 10. Unloading vertical strain fields obtained for each loading level (same scale).

mean value of DIC vertical strain fields was carried out. Results are illustrated in Figure 8 and show a concordance of the two ways of strain evaluation at $20 \mathrm{MPa}$ : during unloading, the mean value of the DIC strain was $0.36 \%$ and the gauge strain value was $0.49-0.17 \%=0.32 \%$.

\subsubsection{Conclusion for the preliminary test at $20 \mathrm{MPa}$}

The results at $20 \mathrm{MPa}$ made it possible to present the methodology and the validation process to determine the mechanical behavior of the sintered material. Firstly, the comparison between gauge results confirmed the quality of the compressive test performed and the control of the sampling. Then, complementary tests showed that there were negligible creep and relaxation in the sintered material to maintain a purely elastic domain during unloading. From the unloading, displacement and strain fields could be extracted. A comparison between the results from the two strain gauges and the vertical strain field from DIC was carried out. The mean strain values obtained by the two routes were closed and confirmed the volumerelated representativeness of the observed surface by DIC in terms of mechanical behavior.

This methodology for one load level could then be extended with a new sample for different load levels in order to determine a load level history on the mechanical behavior.
The non-linear behavior during unloading and a slightly increased deformation with the cycle are also shown, and are discussed in the following.

\subsection{Application to increasing loading}

With the validation of DIC results in the pre-test at $20 \mathrm{MPa}$, the compressive test was extended to the test sequence previously described in Table 2 . To illustrate the loading history in the sintered material, a new sample has been extracted and prepared. The different loading levels were applied to the same sample with increasing loading.

\subsubsection{Strain gauges results}

The mechanical response of this material for different load levels is illustrated in Figure 9.

For each first loading level, a non-linear behavior is observed for the first cycle when the pressure applied was higher than the previous load level. This modification of the behavior can be explained by plasticity, as this nonlinearity appears only during the first cycle and above the threshold of the previously applied pressure.

Note that even if the loading level is limited, stress concentration occur inside the metallic matrix due to the presence of big size particles, as it is illustrated in the following, and that could explained this plastic behavior. 


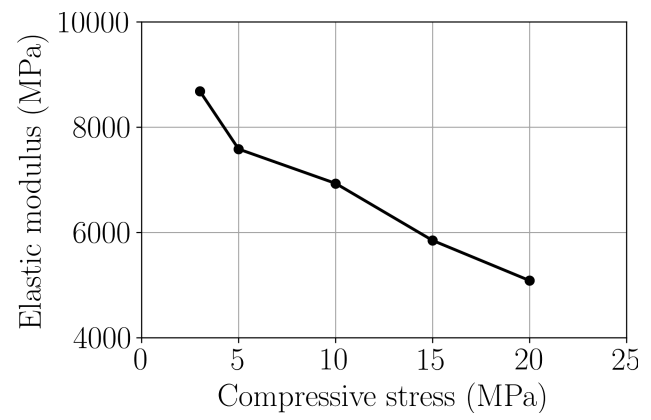

Table 3. New test procedure to validate the loading history.

\begin{tabular}{lrrrrrr}
\hline Level number & 1 & 2 & 3 & 4 & 5 & 6 \\
Load level (MPa) & 20 & 3 & 5 & 10 & 15 & 20 \\
Number of cycles & 1 & 4 & 4 & 10 & 10 & 10 \\
\hline
\end{tabular}

Fig. 11. Evolution of the elastic modulus with increasing load determined from the DIC results.
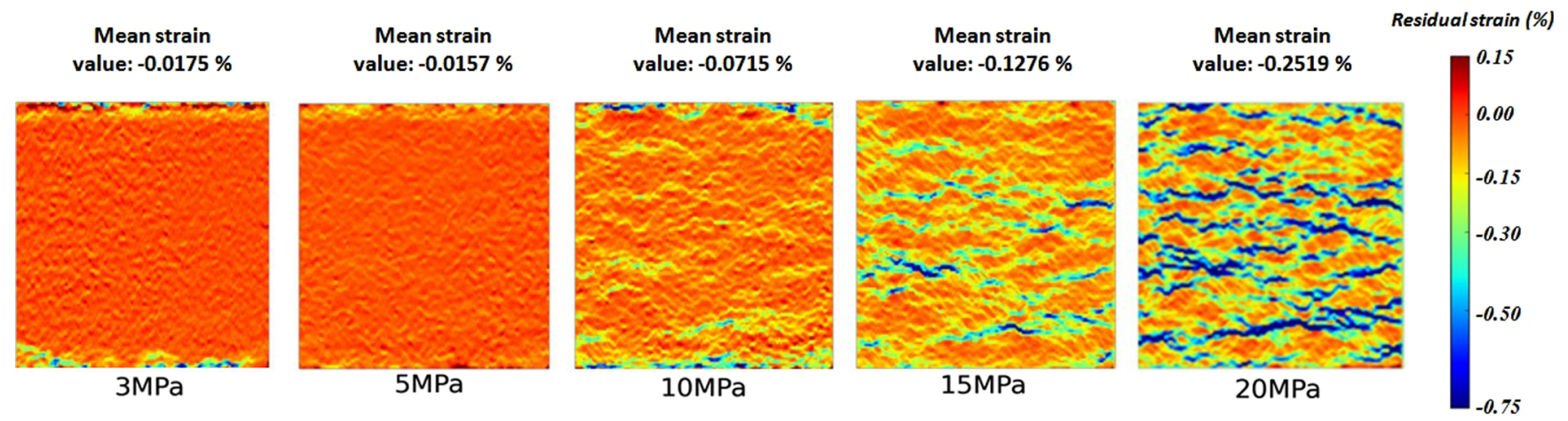

Fig. 12. Residual vertical strain fields obtained for each load level (same scale).

Another main result is the modification of the slope of the loading curves with increasing loading. This is exhibited by the black lines in Figure 9. The slopes were obtained by linking the higher and lower pressure points during the last unloading. They show a decrease of the elastic modulus when increasing loading and a stabilization of the elastic modulus during each cyclic loading. The elastic modulus depends on the maximum pressure applied on the sample, and such an effect can be interpreted as damage to the material, as discussed in the following.

\subsubsection{DIC results for each loading level}

The elastic strain can be determined during the unloading for each load level by a correlation between images 1 and 2 illustrated in Figure 6 . These pictures correspond to the last cycle of a load level.

Figure 10 presents the results of the correlation for the vertical strain field with increasing load.

With the use of the DIC, local strain information could be obtained. One can see that, during the loading, local bands appear, grew and finally coalesce. These bands correspond to high stresses on the material in the concentrated zones. From these fields, the mean values of vertical strain were extracted to determine the evolution of the elastic modulus evolution with the load. This evolution is presented in Figure 11. The image confirms the decrease of elastic modulus when the load was raised.
Using DIC, it is interesting to study the evolution of strain localizations in bands to understand their origin and impact on the material behavior, even more in terms of residual strain when loading increases.

The residual strain was determined by comparing a picture before and after load cycles (respectively pictures 3 and 2 in Fig. 6) in the vertical direction. The results, obtained for the different loading levels, presented the same bands at the same position as that found for the elastic strain (Fig. 12). The elastic and plastic strains are localized in the same areas. Furthermore, at lower pressure, the residual strain was situated at the top and bottom edges of the sample, which was probably due to a surface effect on the loading areas of the sample. From these residual strain fields, mean values have been extracted and plotted at the bottom of the strain fields in Figure 12. At $10 \mathrm{MPa}$, the residual strain value was significant: the localizations of strain in bands start to appear and grow as the loading increases. It means that the elastic limit of the material was reached between 5 and $10 \mathrm{MPa}$.

\subsubsection{Link between mechanical behavior and microstructure}

The mechanical behavior of the sintered material is very complex and exhibits loading history dependency. Moreover, the DIC results presented in Figures 10 and 12 revealed strain localization in bands that grow as the load increases. To understand the phenomena taking place in 


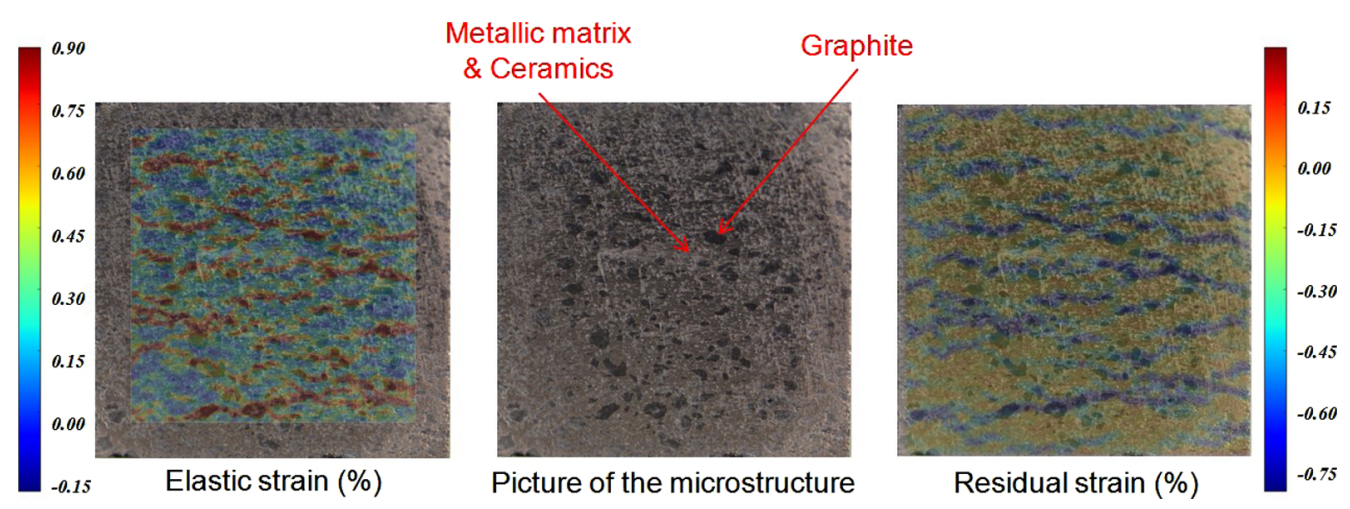

Fig. 13. Vertical strain fields at $20 \mathrm{MPa}$ compared with images of the microstructure.

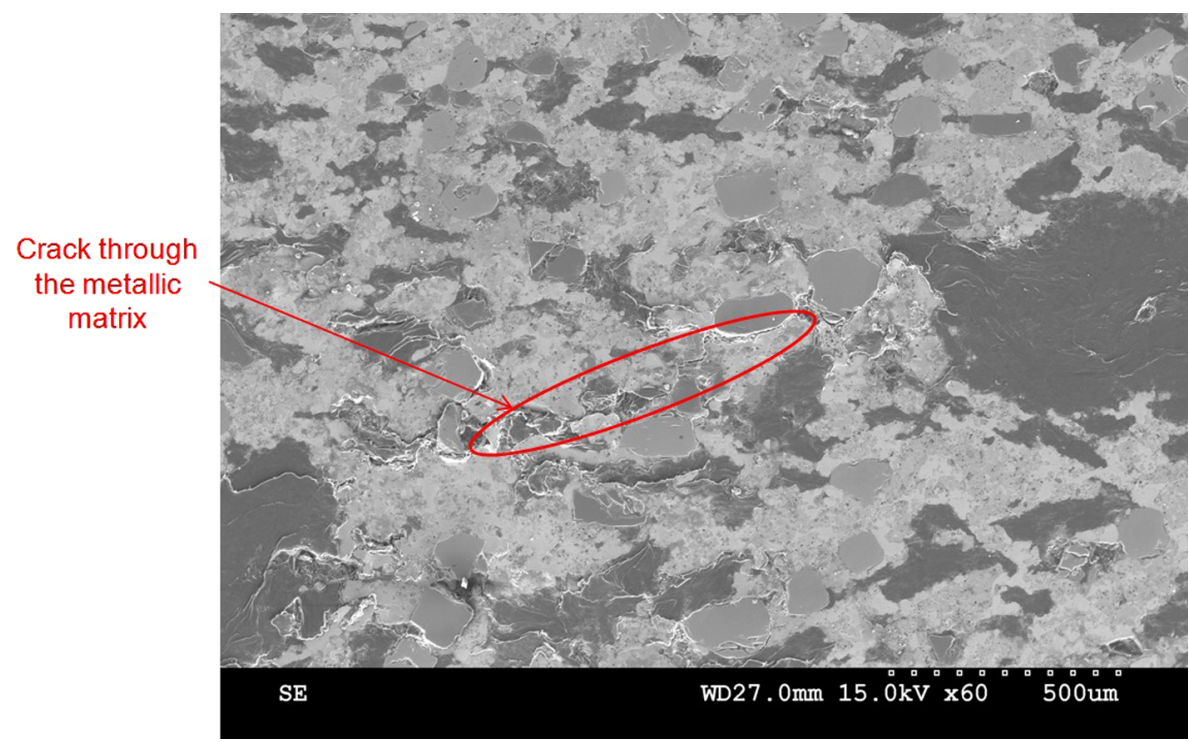

Fig. 14. Image SEM of the macroscopic cracks originated after compressing the material at $60 \mathrm{MPa}$.

the material during loading, the strain fields extracted from elastic and residual strain were superimposed with a picture of the microstructure obtained before applying the surface speckle pattern (Fig. 13). It shows that the highest strains coincide with the areas linking graphite particles on the elastic and residual strain fields. The graphites seem to lead the mechanical behavior of the sintered material. So, even if the material contained different components, this sintered material seemed to have a two-component material behavior (graphite + other containing the metallic matrix).

In the bibliography, similar mechanisms have been identified in compacted graphite cast irons with localizations of strains in bands corresponding to a cluster or an alignment of graphite particles [22-25]. The initiation of these localizations has been explained by the presence of porosities in the graphite particles. As illustrated by Angus [22], the permanent deformation is seen as a plastic strain of the matrix initiated in graphite areas by the presence of cavities. The permanent deformation is especially localized in the vicinity of the graphite particles perpendicular to the loading direction, but also in the matrix linking the graphite particles by stress concentration.
In the sintered material, two types of porosities were found: internal porosities in graphite particles (observed in Fig. 1) and porosities at the interface between the metallic matrix and graphite particles. These voids and a lower elastic modulus of the graphite component can initiate the heterogeneities in the strain field and damage the material by possible cracking of the matrix or loss of cohesion at the interfaces between matrix and graphite particles.

In order to interpret the decrease of the elastic modulus and the strain localization bands, a complementary study was carried out by testing the material to a higher compression level. When the material is tested at $60 \mathrm{MPa}$, several cracks can be observed with the naked eye occurring at the metallic matrix (see Fig. 14). The location of these cracks corresponds to the deformation bands observed in the vertical strain fields. The exact mechanisms leading to the formation of these macro-cracks are still unknown. Nevertheless, it appears that they are formed by coalescence of slip bands and/or micro-cracks created at lower stresses. It has been observed, using synchrotron tomography (at the ESRF-Grenoble, voxel size $=3.5 \mu \mathrm{m}$ ), that the cohesion between graphite and ceramic particles with the metallic matrix is weak, in the virgin material, because interface voids are systematically observed at the particles interfaces (see 


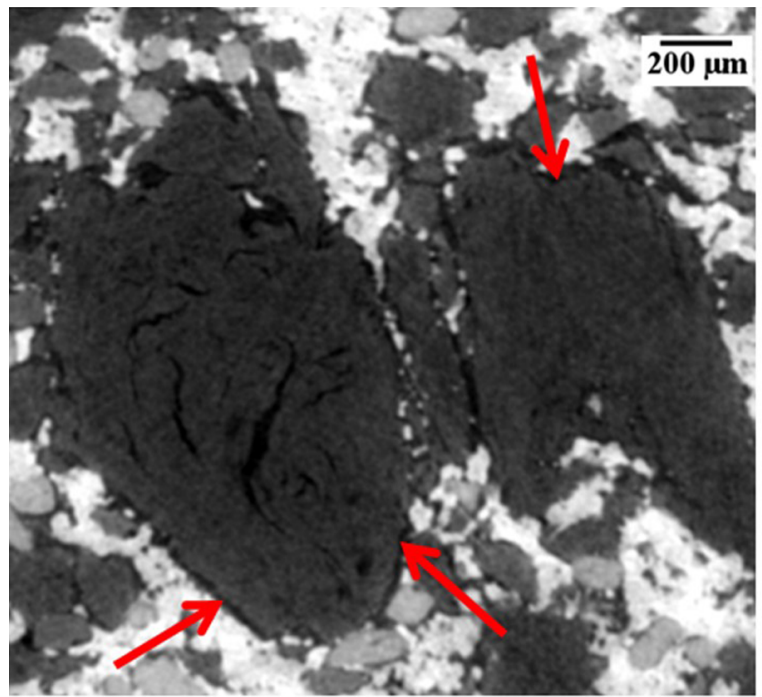

(a)

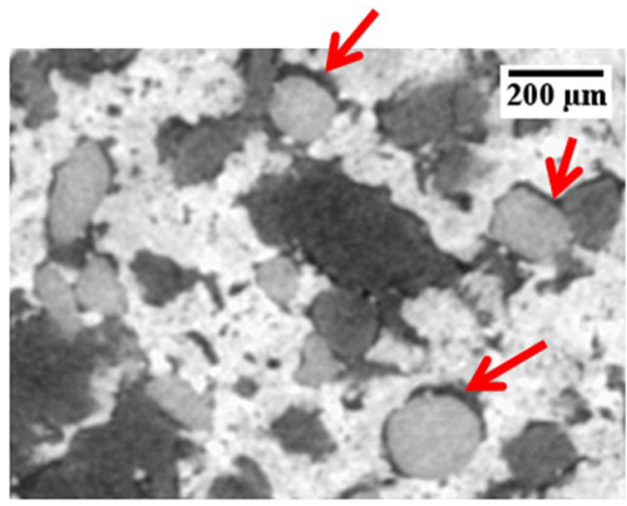

(b)

Fig. 15. 2D micro computed tomography reconstructed slices showing: (a) voids occurring at the interfaces between a graphite particle and the metallic matrix and (b) voids occurring at the interface of a ceramic particle.
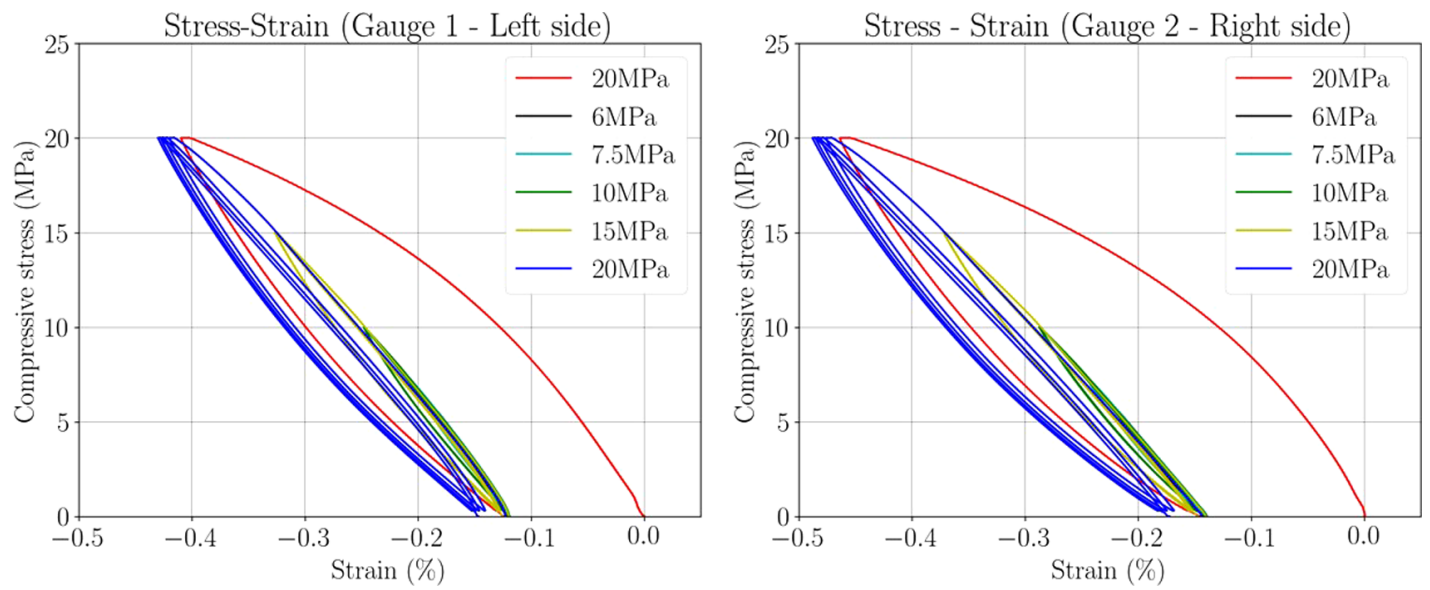

Fig. 16. Stress-strain curves from gauge results for the sequence with a first loading at $20 \mathrm{MPa}$.

Fig. 15). Therefore, it seems likely that the decreasing of elastic modulus phenomenon is mainly controlled by the formation of micro-cracks in the matrix. We consider therefore that micro-cracks with the particle interfaces play a secondary role during loading as they exist before.

\subsubsection{Validation of loading history effect on elastic mechanical properties}

The decrease of the elastic modulus presented in Figure 11 has been interpreted as damage of the material. To confirm the loading history effect of the material for its elastic behavior, a complementary test has been realized according to a test procedure presented in Table 3 . The difference with regard to the previous test procedure was an initial load at $20 \mathrm{MPa}$ with just one cycle.
As in Figure 3 the two gauges do not give exactly the same magnitude probably to parallelism defects, but the succession of cycles after the first loading leads to the same conclusion. By focusing on the slopes of the curves and linking the higher and lower pressure points during the last unloading, the behavior is the same for each cycle (Fig. 16).

These results can be confirmed using the DIC to determine an evolution of the elastic modulus with the same treatment as that described in the previous section.

Figure 17 confirms that there was no evolution, i.e. damage, of the elastic modulus after the first load at $20 \mathrm{MPa}$. The values of the moduli are approximately the same as the modulus obtained previously at $20 \mathrm{MPa}$ (Fig. 11). It means that the sintered material had a loading history effect based on the maximum initial applied loading. 


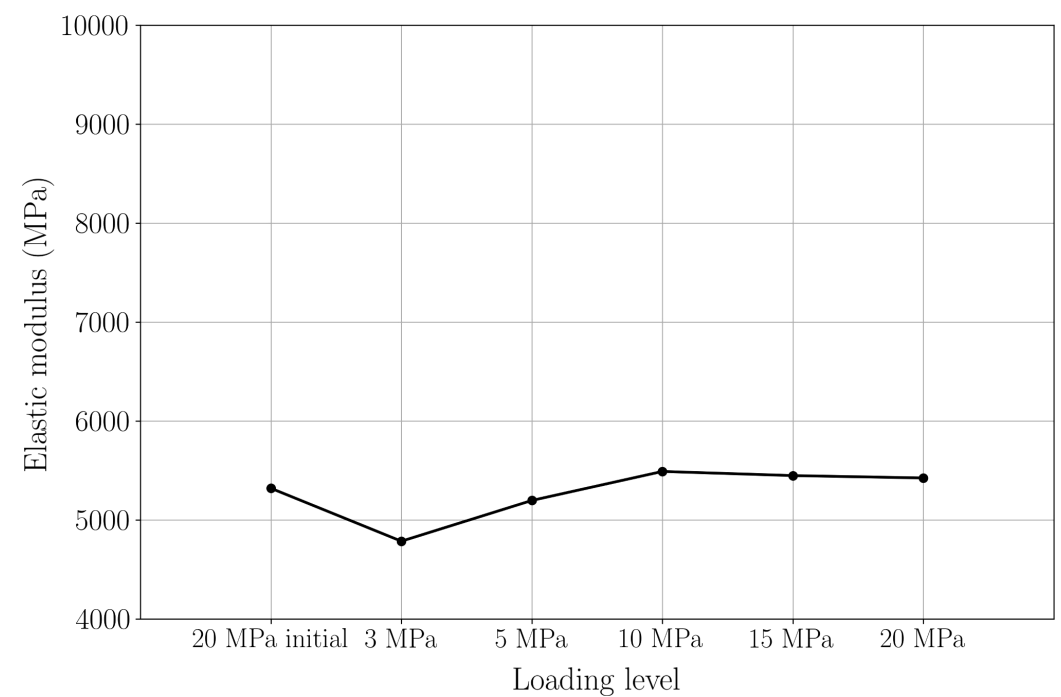

Fig. 17. Elastic modulus sequence with a first loading at $20 \mathrm{MPa}$ and determined from DIC results.

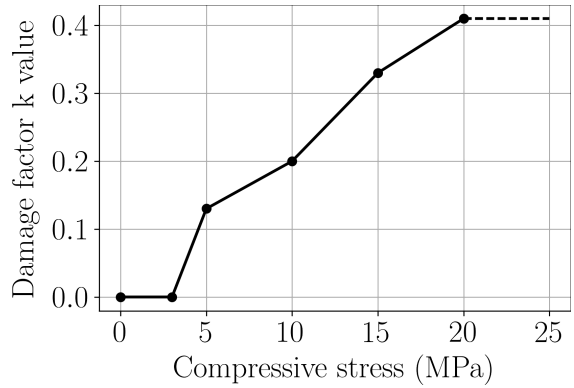

Fig. 18. Evolution of the damage factor $k$ with maximal pressure.

\section{Integration of the mechanical behavior in a finite element model}

The previous section explained the methodology to determine the mechanical behavior of the sintered material when a history loading effect was identified in an elasticplastic with damage context.

Indeed, for the elastic part, the results demonstrated a significant decrease (almost $40 \%$ ) of the elastic modulus by increasing the loading from 3 to $20 \mathrm{MPa}$ and thus, it was necessary to model this complex behavior. For the residual part, the results enabled an identification of the yield strength between 5 and $10 \mathrm{MPa}$. It is clear that this kind of constitutive law was un-trivial and that it was necessary to develop a specific means of taking all of these phenomena into account. In order to consider these behavior extracted from the experimental tests in braking simulations, a user material (UMAT) subroutine was developed within the FE software ANSYS [26]. The mechanical model of the sintered material was considered as elastic-plastic with damage to the elastic part from the maximum stress. This behavior model is sufficient to represent the sintered material at the braking system scale.
This user material subroutine was numerically based on the return mapping developed by SIMO and HUGHES [27], like most card material already available in ANSYS.

According to the maximum loading level reached, experimental tests demonstrated damage to the elastic modulus. This damage was considered by including a damage factor $\mathrm{k}$ on the mechanical properties, represented by a factor $k$ decreasing the starting value of the $i$ directional elastic modulus $\left(E i_{\text {initial }}\right)$ identified for the first load step $(3 \mathrm{MPa})$ in the previous part. For example in the -direction:

$$
E i_{\text {damage }}=(1-k i) \cdot E i_{\text {initial }}
$$

After validation of the development, the UMAT was used to simulate the experimental test presented previously in Table 2. It consists in illustrating that the UMAT made it possible to take into account the history effect from the maximum applied stress on the Young modulus and the plastic strain.

Real dimensions of the sample were used and the applied boundary conditions are: no vertical displacement for the lower surface area of the cube and uniform pressure applied to its upper surface.

The sintered material properties were extracted directly from experimental compressive tests considering a virgin material (no compressive loading was applied on the material after manufacturing). The initial elastic modulus value was $8682 \mathrm{MPa}$ (obtained for the lower pressure $3 \mathrm{MPa}$ ) and the damage factors $(k)$ for the different loading levels were calculated from Figure 11 and are illustrated in Figure 18.

To compare the vertical total strain obtained during the loading of the first cycle between the numerical model using the UMAT and experimental data using DIC, some correlations were carried out. The strain was denoted "total strain" since elastic strain, plastic strain and damage all appear during the loading of the first cycle. 


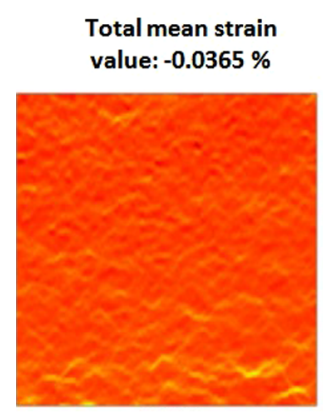

$3 \mathrm{MPa}$

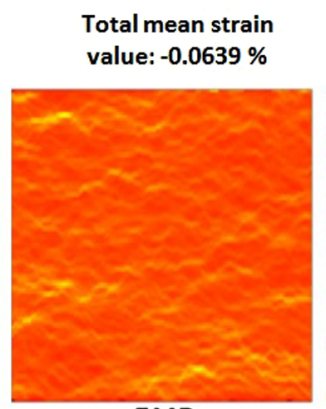

$5 \mathrm{MPa}$

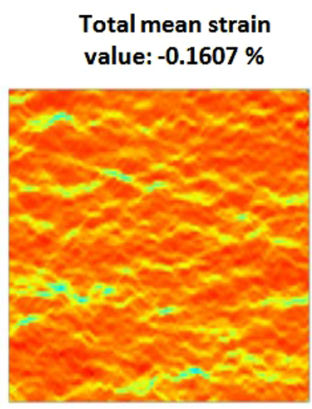

$10 \mathrm{MPa}$

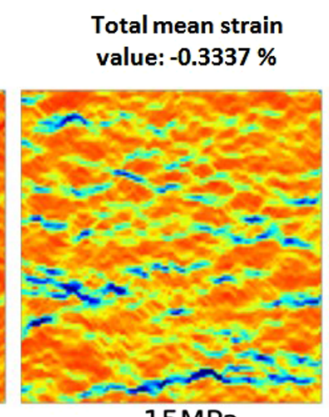

$15 \mathrm{MPa}$

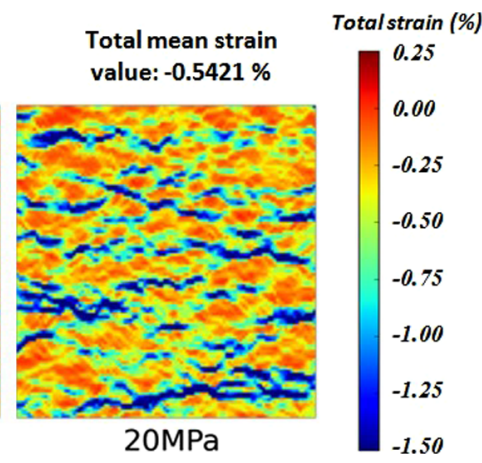

Fig. 19. Total strain obtained with DIC.

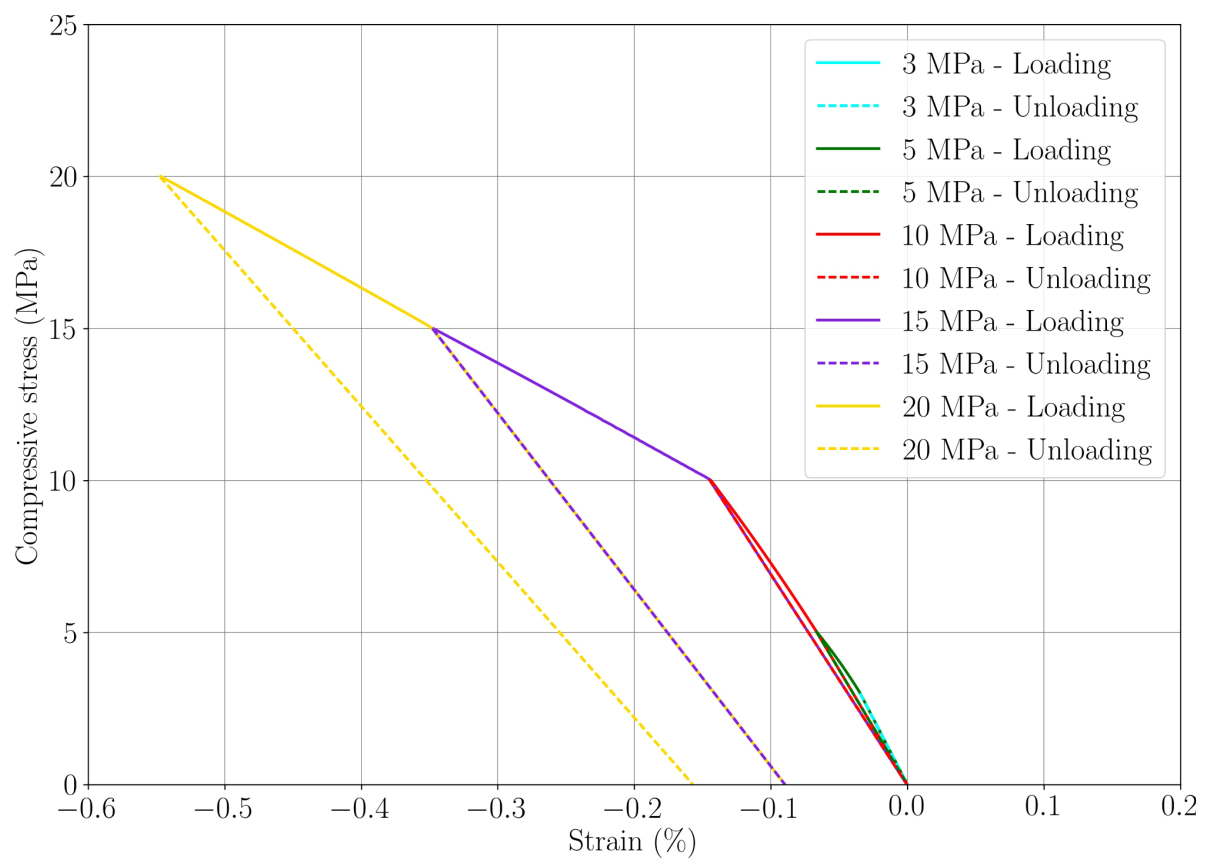

Fig. 20. Total strain obtained with the numerical model.

The total mean strain values have been determined with a correlation between images 3 and 4 illustrated in Figure 6 and are presented in Figure 19.

From these results and other presented in Figure 12, the yield strength has been evaluated to $10 \mathrm{MPa}$. A linear strain hardening modulus has been extracted using equation (2) and its value is determined as $2838 \mathrm{MPa}$.

$$
H=\frac{\sigma_{\max }-\sigma_{0}}{\varepsilon_{\max }^{\text {total }}-\left(\frac{\sigma_{0}}{E_{\text {init }} \cdot\left(1-k_{\max }\right)}\right)}
$$

Figure 20 summarizes the evolution of total strain obtained for each loading level with the numerical model. The evolution of the damage can be observed by comparing the slope of the unloading for the different loading levels and the plastic strain when the applied load returned to zero.

Table 4 summarizes the experimentally and numerically obtained total strain at different loading levels. The comparison between values show similar results between numeric and experimental tests when the loading increases. The coincidence between numerical and experimental values seems logical given the fact that the numerical parameters of the behavior law were identified from experimental data. However, it validates the hypothesis that the sintered material could, in numerical simulations, be represented by an elasto-plastic behavior law with damage from pressure.

The same procedure was used to simulate the second experimental test previously presented in Table 3 with the UMAT. It validates the loading history by comparing with previous results the total mean strain values when an initial load at $20 \mathrm{MPa}$ was added.

Figure 21 presents the stress/strain curves obtained for each loading level in the numerical model using the UMAT. During the initial load of $20 \mathrm{MPa}$, the damage and plastic strain can be observed by evolutions of the slope during loading. 
Table 4. Comparison between the experimental and numerical total strain obtained for each load level.

\begin{tabular}{lccccc}
\hline Load level (MPa) & 3 & 5 & 10 & 15 & 20 \\
Experimental total strain (\%) & -0.0365 & -0.0639 & -0.1607 & -0.3337 & -0.5421 \\
Numerical total strain (\%) & -0.0346 & -0.066 & -0.144 & -0.3470 & -0.5469 \\
\hline
\end{tabular}

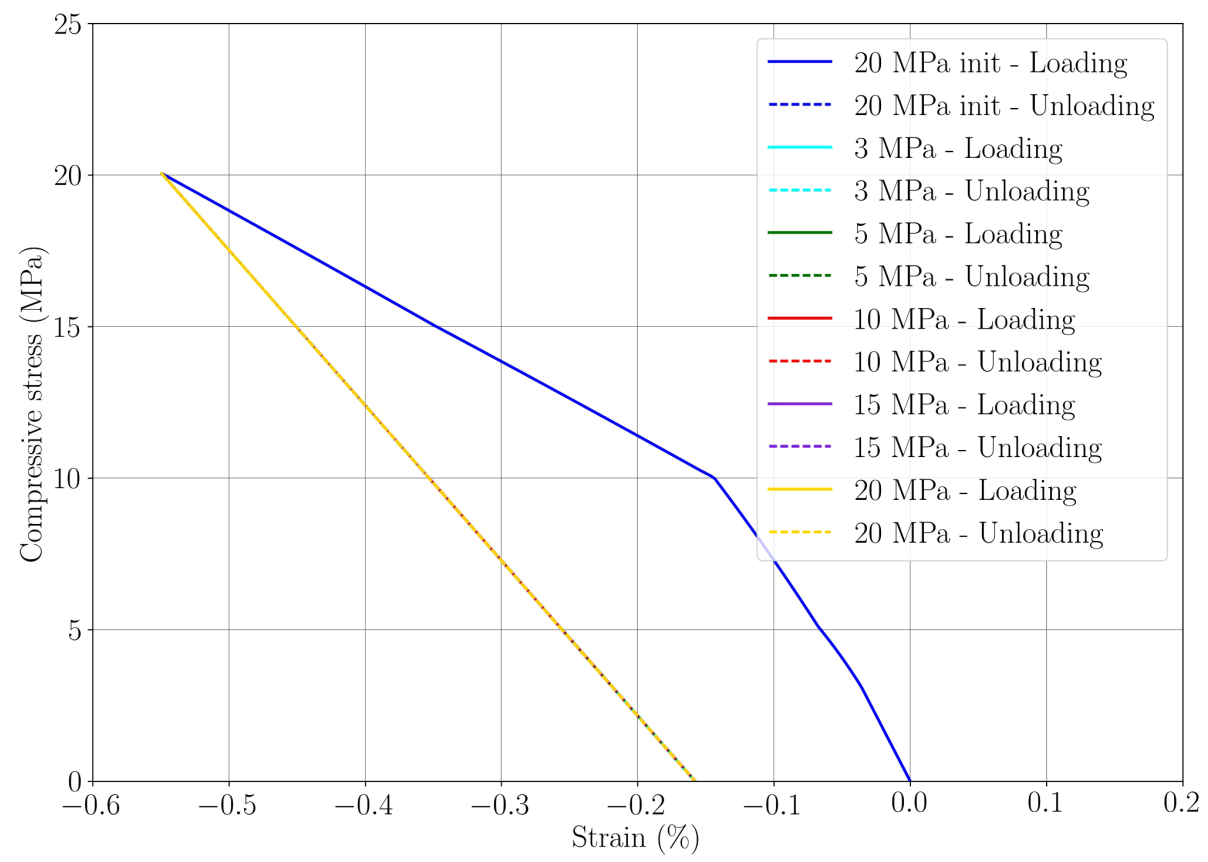

Fig. 21. Total strain obtained with the numerical model when an initial load of $20 \mathrm{MPa}$ was applied.

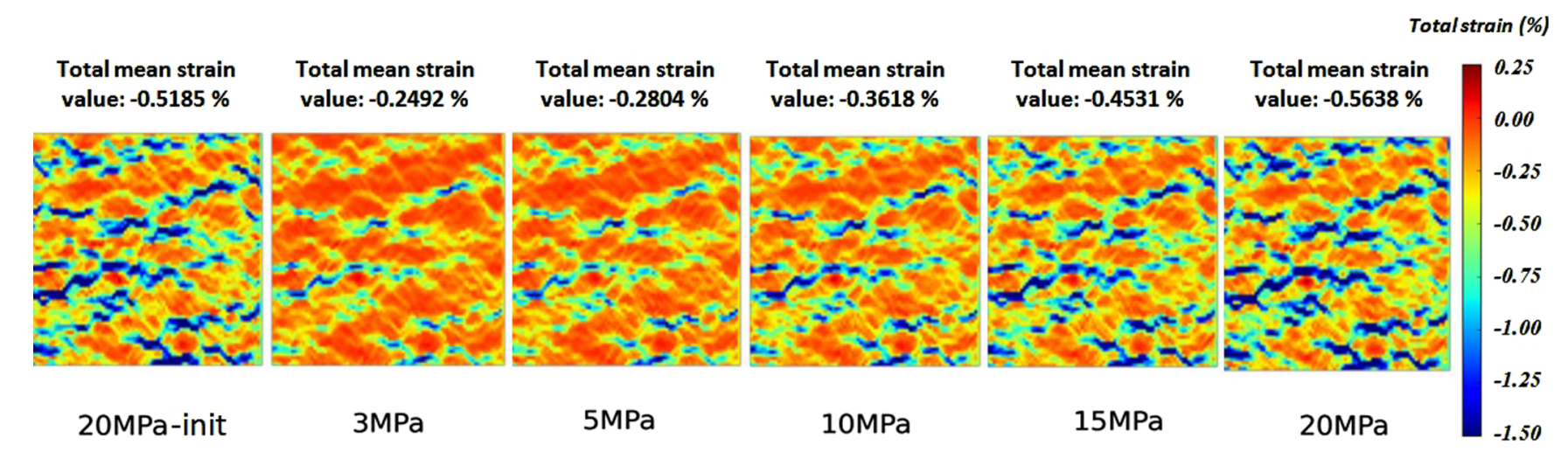

Fig. 22. Total strain obtained with DIC when an initial load at $20 \mathrm{MPa}$ was applied.

After the first loading of $20 \mathrm{MPa}$, all loading levels were below the pressure already applied. There was thus no change in damage or plastic strain, and therefore the stress/strain curves were superimposed with the unloading curve of the initial $20 \mathrm{MPa}$ load.

The total mean strain values were determined with a correlation between images 3 and 4 illustrated in Figure 6 and presented in Figure 22. To obtain the total mean strain, image 3 was the same for each loading level. This image was extracted for the first loading level (initial $20 \mathrm{MPa}$ ). Thus, plastic strains were determined compared to the initial state.

Table 5 summarizes the experimental and numerical total strain with an initial load of $20 \mathrm{MPa}$, as well as the numerical results obtained previously without the initial load. 
Table 5. Comparison between the experimental and numerical total strain obtained for each loading level.

\begin{tabular}{lcccccc}
\hline Load level (MPa) & 20 & 3 & 5 & 10 & 15 & 20 \\
Exp. total strain with a 20 MPa pre-load (\%) & -0.52 & -0.25 & -0.28 & -0.36 & -0.45 & -0.56 \\
Num. total strain with a 20 MPa pre-load (\%) & -0.55 & -0.22 & -0.26 & -0.35 & -0.45 & -0.55 \\
Num. total strain without a 20 MPa pre-load (\%) & - & -0.03 & -0.07 & -0.14 & -0.35 & -0.55 \\
\hline
\end{tabular}

The comparison between values validated once again the choice of the behavior law, and led to the conclusion that one could successfully establish a mechanical behavior law, for a sintered material, integrating a history effect from the maximum loading level applied.

\section{Conclusions}

A methodology to characterize the mechanical behavior of a sintered material used for brake applications was developed. DIC techniques during compressive tests were used to enhance the non-uniformity of strains induced by the material heterogeneity. To validate the volume-related representativeness of the observed face, the results obtained from DIC were compared to counterparts from strain gauge experiments leading to similar mean strain values in an established protocol.

After validation, the DIC results were used to obtain the elastic and residual strain fields. From the former, the evolution of the elastic modulus showed a decrease with increasing load levels. This evolution was interpreted as a damage issue from a load history effect, validated by a complementary test with a pre-load. By using DIC techniques, it was possible to observe the local strain and to link strain mechanisms with the microstructure. With the superimposition of pictures of strain fields and microstructure, the local large strain could be associated with graphite areas giving a better understanding of how the behavior of the individual components controlled the global strain behavior. The main role of the graphite particles was demonstrated and it was shown that the material had a "two-component" behavior at a meso scale despite the complexity of the composition. Elastic damage has been characterized that seem to be linked with cracking in the metallic matrix, thanks to microstructural observations.

Experimental data were employed to develop a user material subroutine taking into account the evolution of the mechanical behavior with pressure. This history effect, illustrated by damage, was used in numerical modeling to describe the experimental compressive test presented in the first part. A comparison between numerical and experimental data validated the characterization of the elastic behavior of the sintered material.

Finally, the behavior laws established for the sintered material from the experimental characterizations using non-linear and loading dependent behavior are directly usable in complex braking simulations.

This methodology has been extended to improve the behavior models by testing different samples to verify the reproducibility of the results, and by taking into account the effect of the temperature, which may provide another load history effect depending on two parameters: the load and the temperature history [28]. Also anisotropic behavior has to be considered in the following in particular because of the shearing loading in braking situation. Even if additional compressive tests in the other directions can be achieved, shear test is also important and has to be developed with the same DIC measurement technique.

Acknowledgements. The present research work was carried out with the project GLGV backed by the SNCF, FAIVELEY TRANSPORT, the LML (Laboratoire de Mécanique de Lille), and the ADEME organism. The authors gratefully acknowledge the support of these institutions.

\section{References}

[1] I.M. Dagwa, A.O.A. Ibhadode, Some physical and mechanical properties of asbestos - free experimental brake pad, J. Raw Mater. Res. 3 (2006) 94-103

[2] D. Brizard, O. Chiello, J.-J. Sinou, X. Lorang, Performances of some reduced bases for the stability analysis of a disc/pads system in sliding contact, J. Sound Vib. 330 (2011) 703-720

[3] E. Wegmann, A. Stenkamp, A. Dohle, Relation between compressibility and viscoelastic material properties of a brake pad, Tech. Rep., SAE Technical Paper, 2009

[4] E. Wegmann, A. Stenkamp, A. Dohle, Mechanical behaviour of friction materials using compression creep tests, 2010

[5] M. Vianello, M. Tirovic, P. Bannister, An improved approach to complex eigenvalue analysis of brake squeal including thermal effects, Tech. Rep., Eurobrake Technical Paper - EB2015-NVH-017, 2015

[6] S. Panier, P. Dufrenoy, D. Weichert, An experimental investigation of hot spots in railway disc brakes, Wear 256 (2004) 764-773

[7] F. Massi, L. Baillet, G. Oliviero, A. Sestieri, Brake squeal: linear and non-linear numerical approaches, Mech. Syst. Signal Process. 21 (2007) 2374-2393

[8] C. Mbodj, M. Renouf, L. Baillet, Y. Berthier, Modeling of carbon/carbon composites under tribological solicitations, in: STLE/ASME 2010 International Joint Tribology Conference, American Society of Mechanical Engineers, 2010, pp. 321-323

[9] N. Hoffmann, M. Fischer, R. Allgaier, L. Gaul, A minimal model for studying properties of the mode-coupling type instability in friction induced oscillations, Mech. Res. Commun. 29 (2002) 197-205

[10] M. Triches Jr, S.N.Y. Gerges, R. Jordan, Analysis of brake squeal noise using the finite element method: a parametric study, Appl. Acoust. 69 (2008) 147-162

[11] P. Alart, F. Lebon, Numerical study of a stratified composite coupling homogenization and frictional contact, Math. Comput. Model. 28 (1998) 273-286 
[12] I. Temizer, P. Wriggers, A multiscale contact homogenization technique for the modeling of third bodies in the contact interface, Comput. Methods Appl. Mech. Eng. 198 (2008) 377-396

[13] F. Barbe, L. Decker, D. Jeulin, G. Cailletaud, Intergranular and intragranular behavior of polycrystalline aggregates. Part 1: Fe model, Int. J. Plast. 17 (2001) 513-536

[14] F. Barbe, S. Forest, G. Cailletaud, Intergranular and intragranular behavior of polycrystalline aggregates. Part 2: results, Int. J. Plast. 17 (2001) 537-563

[15] G. Besnard, F. Hild, S. Roux, Finite-element displacement fields analysis from digital images: application to portevin-le châtelier bands, Exp. Mech. 46 (2006) 789-803

[16] J. Rethore, G. Besnard, G. Vivier, F. Hild, S. Roux, Experimental investigation of localized phenomena using digital image correlation, Philos. Mag. 88 (2008) 3339-3355

[17] S. Avril, M. Bonnet, A.-S. Bretelle, M. Grediac, F. Hild, P. Ienny, F. Latourte, D. Lemosse, S. Pagano, E. Pagnacco, F. Pierron, Overview of identification methods of mechanical parameters based on full-field measurements, Exp. Mech. 48 (2008) 381-402

[18] R. Seghir, J. Witz, L. Bodelot, E. Charkaluk, P. Dufrenoy, A thermomechanical analysis of the localization process at the microstructure scale of a 316L stainless steel, Procedia Eng. 10 (2011) 3596-3601

[19] Y. Li, V. Aubin, C. Rey, P. Bompard, The effects of variable stress amplitude on cyclic plasticity and microcrack initiation in austenitic steel 304L, Comput. Mater. Sci. 64 (2012) 7-11
[20] F. Hild, S. Roux, Digital image correlation: from displacement measurement to identification of elastic properties - a review, Strain 42 (2006) 69-80

[21] R. Seghir, J.F. Witz, S. Coudert, Yadics - digital image correlation $2 / 3 \mathrm{~d}$ software, 2014, http://www.yadics.univlille1.fr

[22] H.T. Angus, Cast iron: physical and engineering properties, Elsevier, 2013

[23] S.D. Voigt, S.D. Holmgren, AFS Transactions (1990), Vol. 98

[24] T. Sjögren, F. Wilberfors, M. Alander, Digital image correlation techniques for analysing the deformation behaviour of compacted graphite cast irons on a microstructural level, in: Applied Mechanics and Materials, Trans Tech Publ, 2011, Vol. 70, pp. 171-176

[25] T. Sjögren, P.E. Persson, P. Vomacka, Analysing the deformation behaviour of compacted graphite cast irons using digital image correlation techniques, in: Key Engineering Materials, Trans Tech Publ, 2011, Vol. 457, pp. 470-475

[26] Ansys v16, SAS IP, Inc., 2016

[27] J. Simo, T. Hughes, General return mapping algorithms for rateindependent plasticity, Const. Laws Eng. Mater.: Theory Appl. 1 (1987) 221-232

[28] R. Mann, V. Magnier, J.-F. Brunel, F. Brunel, P. Dufrénoy, M. Henrion, Relation between mechanical behavior and microstructure of a sintered material for braking application, Wear 386 (2017) 1-16

Cite this article as: R. Mann, V. Magnier, I. Serrano-Munoz, J.-F. Brunel, F. Brunel, P. Dufrenoy, M. Henrion, Non-linear mechanical behavior of a sintered material for braking application using digital image correlation, Mechanics \& Industry 18, 601 $(2017)$ 